\title{
A Política Científica e Tecnológica de Santa Catarina: análise a partir do modelo de coalizões de defesa
}

\author{
Luiz Ricardo de Souza \\ Universidade do Estado de Santa Catarina (ESAG/UDESC) \\ Leonardo Secchi \\ Universidade do Estado de Santa Catarina (ESAG/UDESC)
}

\begin{abstract}
Este artigo utiliza o modelo de coalizões de defesa (Advocacy Coalition Framework - ACF), de Sabatier e Jenkins-Smith (1993), para analisar a prevalência da comunidade científica catarinense como atorchave na formulação da Política Científica e Tecnológica (PCT) de Santa Catarina. A coleta de dados foi realizada a partir de relatórios e documentos oficiais das instituições, bem como de entrevistas realizadas com 10 atores do processo de formulação da PCT que ocuparam funções estratégicas no período de 1989 a 2009, assim classificados: 1) comunidade científica; 2) burocratas; 3) designados politicamente; 4) empresários; 5) políticos. A análise dos dados teve como conceitos sensíveis aqueles presentes no modelo de coalizões de defesa: a) o papel dos atores; b) sistemas de convicções e recursos; c) trajetórias da política pública; d) características da política pública; e) conteúdo da política pública. Foram identificadas as conexões entre os atores, suas convicções, estratégias, recursos e constrangimentos. A pesquisa conclui que a comunidade científica exerce um papel de destaque na formulação da política científica e tecnológica catarinense, sendo prevalente na formulação da PCT em todo o período analisado. Em relação aos empresários, políticos e burocratas, não se identificou uma atuação destacada e contínua desses atores. Entretanto, os designados politicamente, que na maioria das vezes são recrutados no seio da comunidade científica, exerceram papel importante na formulação e na reafirmação do sistema de convicções da comunidade científica. Em relação às principais trajetórias que ajudam a explicar as mudanças da PCT catarinense no período analisado, a trajetória "aprendizagem orientada pela política pública" destaca-se perante as demais.
\end{abstract}

Palavras-chave: política científica e tecnológica; coalizões de defesa; comunidade científica; Santa Catarina; política pública.

Política de Ciencia y Tecnología en Santa Catarina, Brasil: análisis a partir del modelo de coaliciones de defensa

Este artículo utiliza el modelo de coaliciones de defensa (Advocacy Coalition Framework - ACF), de Sabatier y Jenkins-Smith (1993), para analizar la prevalencia de la comunidad científica como actor

\footnotetext{
"DOI: http://dx.doi.org/10.1590/0034-76121557

Artigo recebido em 28 abr. 2013 e aceito em 27 fev. 2014.
} 
clave en el desarrollo de la Política Científica y Tecnológica (PCT) en el estado de Santa Catarina - Brasil. La recolección de datos se llevó a cabo a partir de informes oficiales y documentos de las instituciones involucradas en la PCT, así como entrevistas con 10 actores formuladores de la PCT que ocuparon un rol estratégico en el período 1989-2009. Los actores fueron clasificados de la siguiente manera: 1) comunidad científica; 2) burócratas; 3) designados políticamente; 4) empresários; 5) politicos. El análisis de los datos utilizó los conceptos sensibles presentes en el modelo de coaliciones de defensa: a) el papel de los actores; b) los sistemas de creencias y los recursos; c) las trayectorias de la política pública; d) las características de la política pública; e) el contenido de la política pública. Se identificaron conexiones entre actores, sus creencias, estrategias, recursos y limitaciones. La investigación concluye que la comunidad científica juega un papel de liderazgo en la formulación de la política científica y tecnológica en Santa Catarina, siendo actor predominante que en la formulación del PCT a lo largo del período de análisis. En cuanto a los empresarios, los políticos y los burócratas, no se identificó una acción importante y continua de estos actores en el proceso. Sin embargo, los designados políticamente, que a menudo son reclutados en la comunidad científica, juegan un papel importante en la formulación y reafirmación del sistema de convicciones de la comunidad científica. En cuanto a las principales trayectorias de política pública, el "aprendizaje guiado por la política pública" es la trayectoria que se destaca sobre las demás.

Palabras clave: política de ciencia y tecnologia; coaliciones de defensa; comunidad científica; Brasil; políticas públicas.

\section{Science and Technology Policy in Santa Catarina, Brazil: an application of the advocacy coalition framework}

This article uses the Defense Coalition model, proposed by Sabatier and Jenkins-Smith (1993), to analyze the prevalence of Santa Catarina scientific community as a key factor in the development of the Science and Technology Policy (STP) at Santa Catarina state, Brazil. Data collection relied on official reports and documents from the institutions involved in the STP as well as interviews with 10 actors in the creation of the STP process who occupied strategic roles in the period of 1989-2009, categorized as follows: 1) scientific community, 2) bureaucrats; 3) politically chosen ; 4) business owners and 5) politicians. The data analysis relied on the sensitizing concepts used in the defense coalition model a) the role of actors; b) belief system and resources; c) paths of public policy; d) characteristics of the public policy; e) content of the public policy. Connections between actors, their beliefs, strategies, resources and constraints were identified. The research concludes that the scientific community plays a leading role in the formulation of science and technology policy in Santa Catarina, and hold a prevalent role in the creation of the PCT throughout the analyzed period. Regarding business owners, politicians and bureaucrats, the research did not identify a prominent and continuous role of these actors. However, the political chosen ones, who often are recruited within the scientific community, played an important role in reaffirming the shaping of the belief system in the scientific community. Regarding the main trajectories that help explaining the changes of Santa Catarina PCT in the analyzed period, the trajectory "public policy-oriented learning" seems to have an edge over the other trajectories.

Keywords: scientific and technological policy; defense coalitions; scientific community; Santa Catarina; Brazil; public policy. 


\section{Introdução}

Ao longo do século XX a ciência e tecnologia ascenderam à condição de motores do desenvolvimento econômico. Desde a publicação do relatório intitulado Science: the endless frontier, em 1945, elaborado pelo diretor da Agência de Pesquisa Científica e Desenvolvimento Norte-americana (Office of Scientific Research and Development), Vannevar Bush, a ciência e a tecnologia adquiriram status nunca antes concedido à área.

Ao longo dos últimos 60 anos, a Política Científica e Tecnológica (PCT) adquiriu vários formatos, adotou inúmeros instrumentos e transformou-se de uma política meio, de caráter transversal, em uma política com finalidade própria. As alterações pelas quais a PCT passou são fruto dos condicionantes históricos, econômicos, culturais e, principalmente, do jogo político ao qual todas as políticas públicas são submetidas.

Nesse mesmo período, os estudiosos do tema observaram mudanças significativas no âmbito da PCT, principalmente derivadas do modo de produção, reprodução e disseminação do conhecimento. A publicação intitulada The new production of knowledge, de Michael Gibbons e colaboradores (1994), buscou demonstrar como o conhecimento científico e tecnológico passou do que os autores chamaram de "modo 1" para o "modo 2". Segundo Schwartzman, Bath e Biato (2001), o "modo 1" é caracterizado pelo enfoque acadêmico; impulsionado pelo pesquisador; baseado em disciplinas; as instituições de pesquisa são autônomas e os pesquisadores são recompensados pelas publicações; e a produção de conhecimento segue um padrão linear, originando-se na pesquisa básica e culminando na aplicada. Para o autor, o "modo 2" é focado em problemas e possui um caráter interdisciplinar; as instituições de pesquisa estão vinculadas aos usuários - empresas, agências de fomento; os incentivos originam-se dos produtos comercializáveis; a sequência linear do desenvolvimento é rompida dando espaço para o conhecimento desenvolvido por meio de aplicações.

Esta mudança, do "modo 1" para o "modo 2", constituiu o cenário para atuação dos três principais atores envolvidos no processo da PCT: a comunidade científica, os burocratas e os empresários. Cada um deles adota estratégias, usa recursos e molda comportamentos buscando maximizar seus interesses e imputar à PCT sua visão específica. Entretanto, renomados pesquisadores do campo, como Gibbons e colaboradores (1994), Nowotny e colaboradores (2001), Etzkowitz e Leydesforff (2000), admitem a prevalência da comunidade científica em relação aos demais atores envolvidos na PCT. Para Dagnino (2006:192), a PCT "parece ser, em todo o mundo, a política pública mais eficazmente capturada pelo seu ator central - a comunidade científica". Essa posição foi analisada por Sabatier e Mazmanian (1979), os quais afirmaram que um ator dominante no âmbito de uma política pública pode vir a atuar como se ela fosse sua propriedade.

Com a mudança em curso, do "modo 1" para o "modo 2", se esperava um comportamento mais adequado da comunidade de pesquisa em relação aos demais atores (Dagnino, 2006), fato que parece não se confirmar, mantendo-se a concentração do poder decisório e a capacidade de influenciar a PCT por parte do ator dominante, reforçando a assimetria do mesmo em relação aos demais atores envolvidos. 
Para Dagnino (2007), a instituição científica, vista no passado como uma sociedade ideal, hoje constitui uma elite profissional, e revela-se aos olhos do poder tão pouco separada das contingências, das pressões e dos compromissos políticos ou econômicos como qualquer outro grupo profissional. O mesmo autor destaca que pesquisadores norte-americanos, ao analisar a ciência e tecnologia enfocando o poder no aparato científico, concluíram que este se correlacionava imperfeitamente com o sucesso científico, ou seja, no apoio à pesquisa ou na distribuição de recursos, o poder derivava de contatos no seio das burocracias que davam suporte à ciência, e não do mérito das propostas.

Neste estudo optou-se por analisar a PCT a partir do modelo de coalizões de defesa (Advocacy Coalition Framework - ACF), que foi apresentado originalmente em 1988, por Sabatier e Jenkins-Smith ${ }^{1}$ (Sabatier e Weible, 2007).

O modelo busca compreender o processo político baseado no contexto da política. Segundo Weible e Sabatier (2009), o modelo é baseado na integração dos estágios do ciclo de políticas públicas, com ênfase na definição dos problemas, formulação, implementação e avaliação da política, considerando aspectos top down e bottom up para a análise. A principal categoria de análise do modelo ACF são as coalizões de defesa. Esse modelo enfatiza aspectos como o aprendizado e o comportamento das coalizões envolvidas, bem como as alterações na política, em longos períodos de tempo.

Para Dias (2009), a política científica pode ser compreendida como o produto da tensão existente entre "a agenda da ciência" — o conjunto de interesses relativamente articulados da comunidade científica - e "as agendas da sociedade", que envolvem uma grande pluralidade de atores e interesses. Entretanto, o autor destaca que a PCT atende fundamentalmente aos interesses da comunidade científica e, em menor medida, da burguesia industrial nacional, no caso brasileiro.

Identifica-se uma escassez de estudos sobre políticas públicas com a abordagem da análise de política e uma rara existência de estudos que enfoquem a dinâmica da formulação da PCT em contexto subnacional. Para contribuir para o preenchimento dessa lacuna, o presente estudo tem como objeto a PCT em Santa Catarina, no período de 1989 a 2009. Esse período foi especificamente selecionado por abranger desde a ascensão da ciência e da tecnologia à agenda formal do governo do estado, fato evidenciado pela criação do Fundo Rotativo de Fomento à Pesquisa Científica e Tecnológica do Estado de Santa Catarina (Funcitec), em 5 de junho de 1990, até a regulamentação da Lei Catarinense de Inovação pelo Decreto no 2.372 , de 9 de junho de 2009, dispositivo que estabeleceu os procedimentos fundamentais para o seu entendimento e a formalização dos atos legais.

Tendo em vista a problemática apresentada, e considerando a importância de se conhecer a realidade do estado de Santa Catarina em função do seu destaque em nível nacional no que diz respeito à área de $C \& T$, este artigo se propõe a analisar a prevalência da comunidade

\footnotetext{
${ }^{1}$ Para uma visão da evolução do modelo de coalizões de defesa, ver Sabatier (1986), Sabatier e Jenkins-Smith (1993), Sabatier e Weible (2007) e Weible e Sabatier (2009).
} 
científica na formulação da PCT de Santa Catarina, no período de 1989 a 2009. O estudo justifica-se não apenas em função da relevância que a área de ciência e tecnologia adquiriu nas últimas décadas, mas também porque lança um olhar a respeito dos aspectos mais subjetivos em torno da formulação de políticas na área ao adotar o enfoque de análise de política. Esse enfoque, ainda pouco utilizado, contribui para identificação de elementos que influenciam as políticas e que, muitas vezes, não são explicitados.

Além desta Introdução, o artigo estrutura-se em outras quatro seções, que indicam os construtos teóricos que sustentam a pesquisa, os procedimentos metodológicos adotados, a apresentação dos resultados e as discussões e considerações finais do estudo.

\section{Modelo de coalizões de defesa}

Para Dias (2009:30), as coalizões de defesa (Advocacy Coalition Framework - ACF) "podem ser entendidas como grupos de atores que se organizam, formal ou informalmente, com o objetivo de exercer pressão sobre uma determinada política pública, e assim, influenciar seu resultado". Esse modelo enfatiza aspectos como o aprendizado e o comportamento das coalizões envolvidas, bem como as alterações na política, em longos períodos de tempo.

O modelo ACF busca compreender e analisar os fenômenos envolvidos nas mudanças políticas. Para Oliveira (2011), enfatiza aspectos como: a) a importância de comunidades políticas, redes e subsistemas envolverem atores de instituições públicas e privadas e de múltiplos níveis de governo; b) a relevância da informação substantiva na política pública. É fundamental adotar o subsistema como escala de estudo, devido às complexidades envolvidas na análise de cada setor específico da política pública; c) o papel crítico dado às elites da política pública em relação ao público em geral.

A figura 1 apresenta o modelo ACF de forma esquemática, de acordo com Sabatier e Jenkins-Smith (1993). A ACF mostra uma visão geral das coalizões envolvidas no subsistema de política, os fatores exógenos que influenciam o subsistema e afetam as oportunidades e constrangimentos dos atores. Nos próximos itens serão abordadas as variáveis consideradas no modelo.

\subsection{Subsistema de políticas públicas}

O subsistema é a unidade primária de análise e o insumo básico do modelo. Na ACF distinguem-se o subsistema da política pública e o sistema político amplo. Para a ACF, o subsistema da política pública é susceptível a: "efeitos externos do desenvolvimento do amplo sistema político; parâmetros relativamente estáveis; estruturas de oportunidade de coalizão; recursos e constrangimentos de curto prazo dos atores do subsistema" (Sabatier e Weible, 2007:202). 


\section{Figura 1}

\section{Diagrama do modelo de coalizão de defesa (ACF)}

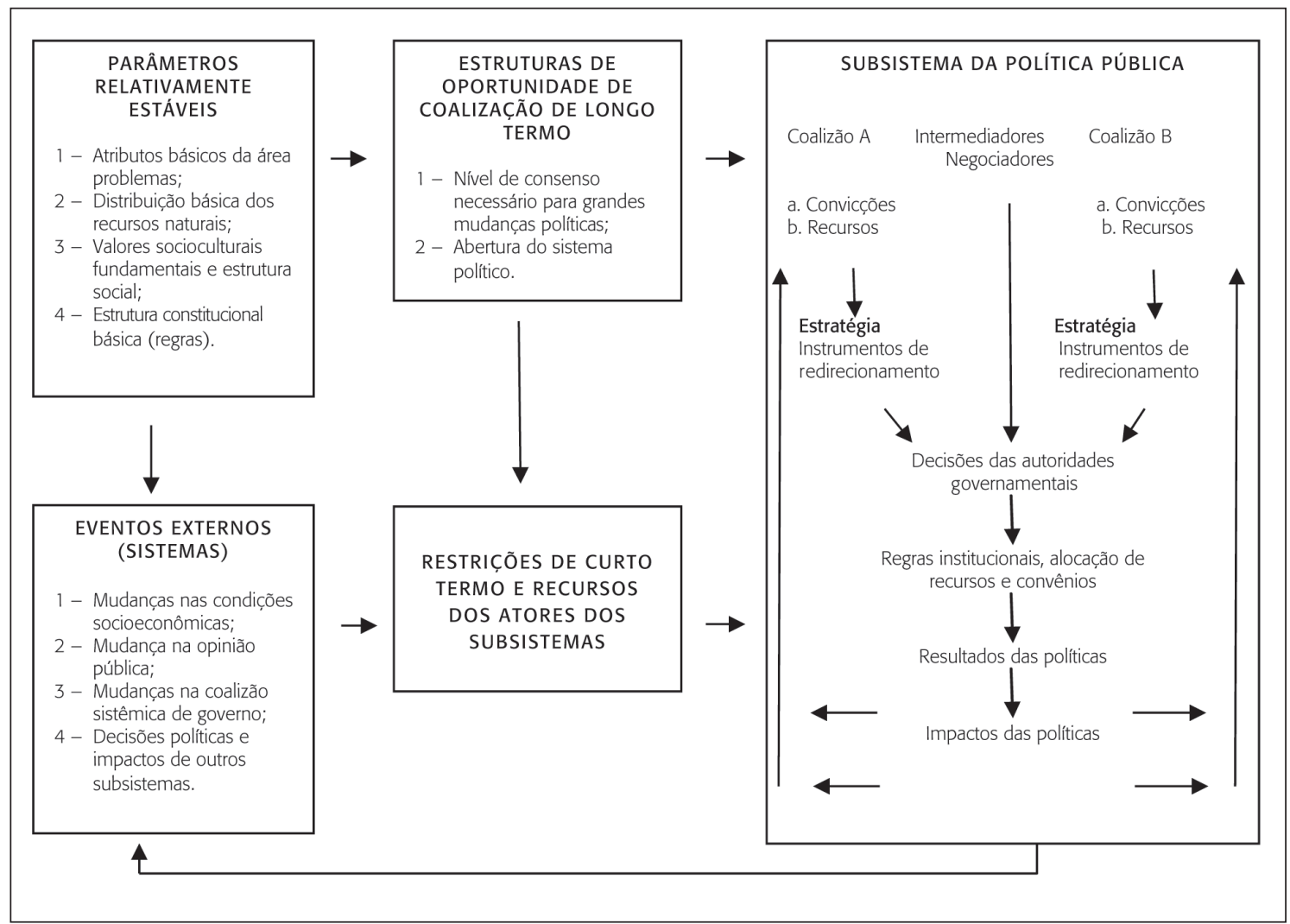

Fonte: Sabatier e Weible (2007:202), tradução de Oliveira (2011:18).

A ACF assume que o processo de políticas em sociedades modernas é tão complexo, tanto no aspecto substantivo do campo quanto no legal, que os participantes devem se especializar, se eles pretendem influenciar o processo. Essa especialização ocorre "dentro de um subsistema composto por participantes que mantêm, com certa regularidade, influência política naquele subsistema" (Sabatier e Weible, 2007:192).

Um subsistema é caracterizado por uma dimensão funcional/substantiva e por uma territorial, que nesta pesquisa se traduzem em: política pública científica e tecnológica (dimensão funcional, substantiva) de Santa Catarina (dimensão territorial). Sabatier e Weible (2007) destacam a dificuldade de delimitar o escopo de um subsistema, quando da existência de sobreposição ou coexistência com outros níveis de subsistemas, citando como exemplo uma agência de habitação local, que é parte de um subsistema local de habitação inserido em um subsistema estadual e federal. 


\subsection{As coalizões, os sistemas de convicções e os recursos}

Para a ACF, as coalizões são formadas em torno de convicções, opiniões, ideias e objetivos partilhados pelos atores envolvidos no processo de política pública. Oliveira (2011) destaca que esse conjunto de convicções e ideias, unido aos recursos políticos, auxilia na delimitação das coalizões e concretiza seus objetivos e interesses.

Segundo Weible e Sabatier (2009), na ACF há um deslocamento do foco nos interesses para o foco nas convicções e ideias. Esse deslocamento distingue a proposta da ACF da abordagem da escolha racional, a qual assume que os atores são autointeressados e guiados por cálculos econômicos de utilidade. Sabatier (1991) também argumenta que as convicções, muita vezes, são incorporadas nos discursos de defesa da política, sendo mais fácil identificálas do que os verdadeiros interesses dos atores envolvidos.

O sistema de convicções da ACF identifica três categorias estruturais: as convicções de núcleo profundo, as de núcleo na política pública e as de aspectos secundários. ${ }^{2}$ As convicções de núcleo profundo são sustentadas em alicerce normativo e em axiomas ontológicos que definem a visão de indivíduo, sociedade e mundo. Em um nível intermediário encontram-se as convicções com núcleo na política pública, configuradas pela questão substantiva do subsistema ou geográfica, pela percepção causal, estratégias básicas e posições políticas para se executar as conviç̧ões de núcleo profundo em um dado subsistema político (Weible e Sabatier, 2009; Sabatier e Weible, 2007). As convicções com núcleo na política são as ideais para formar as coalizões e definir a coordenação dos membros. Esse nível intermediário de convicções é, em geral, resistente a mudanças, mas, no entanto, as logra mais facilmente do que as de núcleo profundo. A mudança normalmente ocorre em resposta a novas experiências ou informações. No terceiro nível são identificadas as convicções de aspectos secundários, que abrangem considerações instrumentais sobre como implementar a política, sendo essas as mais suscetíveis a mudanças ao longo do tempo (Weible e Sabatier, 2009; Sabatier e Weible, 2007).

Para Oliveira (2011), os atores pertencentes a uma coalizão demonstram consenso em questões do núcleo da política pública e discordam mais a respeito de aspectos secundários. A autora também destaca que "as mudanças no nível de convicções de núcleo na política são usualmente resultantes de perturbações ocasionadas por fatores não cognitivos externos ao subsistema" (Oliveira, 2011:23).

A estrutura hierárquica das convicções nas coalizões de defesa é apresentada pelo diagrama a seguir, conforme Parsons apud Oliveira (2011:24).

\footnotetext{
${ }^{2}$ N. do T. "deep core beliefs" - convicções de núcleo profundo; "policy core beliefs" — convicções de núcleo na política pública; "secondary beliefs" — convicções de aspectos secundários.
} 
Figura 2

\section{Diagrama da estrutura de convicções da ACF}

(convicções e normas fundamentais que se aplicam a todos os subsistemas políticos)

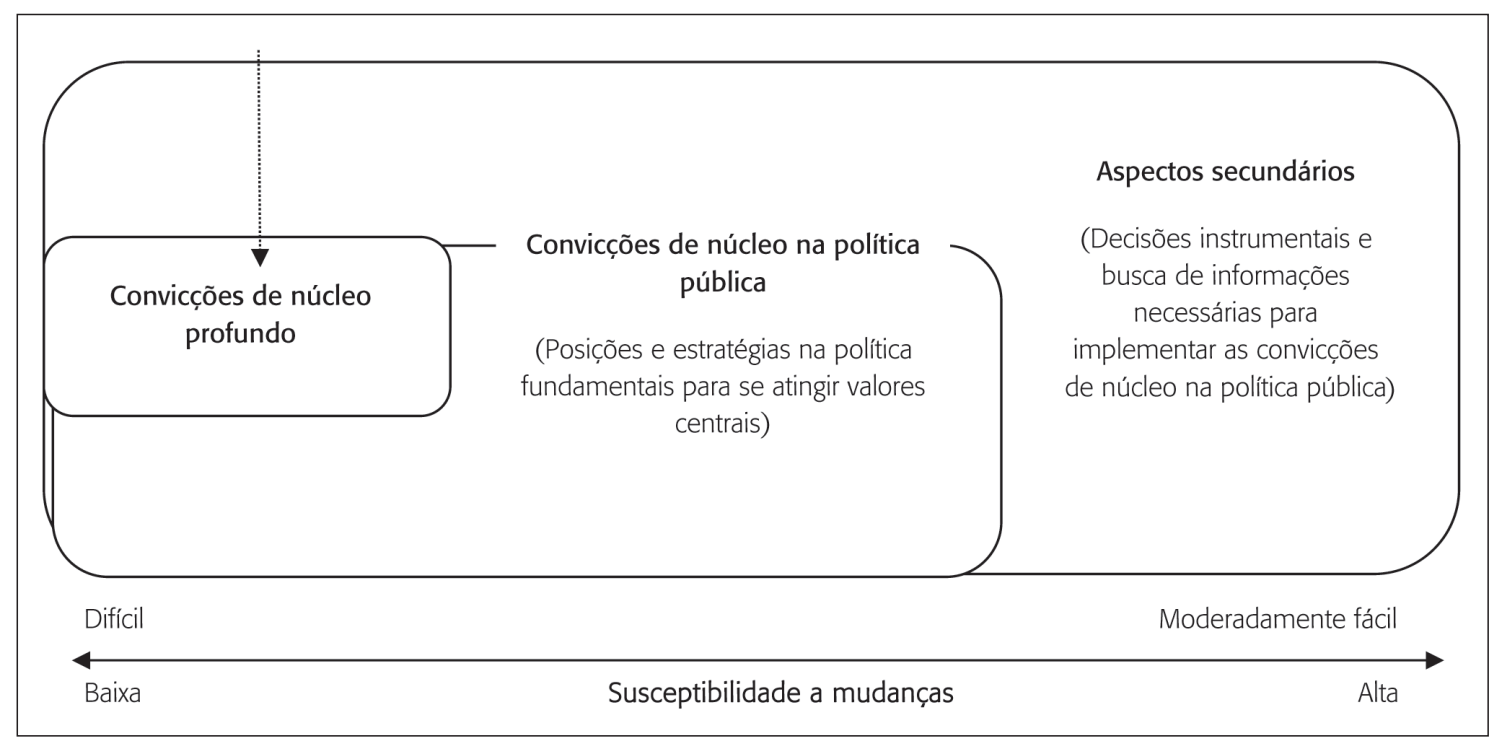

Fonte: Oliveira (2011:24).

Sabatier e Weible (2007) identificam seis tipos de recursos utilizados por coalizões:

i) A participação de atores com autoridade formal institucionalizada, como fortalecimento dos recursos da coalizão. Os autores citam como exemplo o envolvimento de servidores de agências, legisladores e alguns juízes, e destacam que esse recurso é uma das características mais importantes que diferem as coalizões majoritárias das minoritárias;

ii) A opinião pública, como suporte à coalizão. Normalmente, uma típica estratégia é tentar ganhar o apoio da opinião pública visando influenciar as decisões acerca da política;

iii) Informações: estudos que abranjam qualificadamente as alternativas e as relações custobenefício podem fomentar a solidificação da coalizão e podem configurar oportunidades para desqualificar as alternativas dos opositores;

iv) Mobilização de tropas: elites políticas podem usar o público, com abertura para compartilhar suas convicções e inclusive engajá-lo em atividades políticas como a captação de recursos para campanhas;

v) Recursos financeiros podem financiar estudos, mobilização, campanhas na mídia e think tanks que produzam informações relevantes.

vi) Liderança experiente pode criar uma visão atrativa da coalizão. A literatura sobre empreendedores de políticas públicas destaca o papel de lideranças experientes na criação de uma visão atrativa da coalizão. 
As ações dos atores do subsistema desenvolvem-se mediante diferentes estratégias usadas pela coalizão de defesa. Nas aplicações da ACF, identifica-se um foco maior nos sistemas de convicções do que nos recursos das coalizões (Sabatier e Weible, 2007).

\subsection{Trajetórias para as maiores mudanças na política pública}

A aplicação da ACF na análise de políticas públicas identificou quatro principais trajetórias que explicam as mudanças nas convicções e na política pública em longos intervalos de tempo: 1) aprendizagem orientada pela política pública; 2) choques externos; 3) choques internos; e 4) impasse de política (policy stalement) (Sabatier e Weible, 2007).

Segundo Sabatier e Jenkins-Smith (1993:42) a aprendizagem orientada pela política pública é um processo que envolve mudanças relativamente duradouras das convicções e intenções comportamentais resultantes da experiência e que almeja o êxito ou a revisão dos preceitos fundamentais do sistema de convicções dos indivíduos ou de coletividades, tais como as coalizões de defesa.

A ACF não entende os processos políticos como meras disputas entre interesses antagônicos, mas sim como processos de aprendizagem (Oliveira, 2011). Advogando a favor de suas convicções, os atores entram em processos de aprendizagem e tentam traduzir seus ideais em políticas. Oliveira (2011:28) destaca que "as convicções funcionam como variáveis dependentes, que podem ser influenciadas por processos de aprendizagem".

Oliveira (2011) destaca que a ACF considera que a aprendizagem é facilitada pelo debate instruído. Ao enfatizar a necessidade de que ambos os lados do debate tenham capacidades técnicas apropriadas, a aprendizagem passa a exigir fóruns relativamente apolíticos "nos quais os especialistas das respectivas coalizões seriam forçados a se confrontarem uns com os outros" (Sabatier, 1987:679). As variáveis centrais que governam tais formas são sustentadas por critérios que envolvem o prestígio profissional, normas de especialização e revisão paritária (Fischer apud Oliveira, 2011:28), elementos tradicionais no âmbito da PCT.

Segundo Sabatier e Weible (2007), perturbações externas, mudanças socioeconômicas, resultados de outros subsistemas ou desastres, podem alterar a agenda e atrair a atenção pública e dos gestores públicos, mas os autores ressaltam que esses elementos podem não ser suficientes para provocar mudanças na política pública.

Sabatier e Jenkins-Smith (1993) advertem que os choques externos oferecem uma oportunidade para grandes alterações na política pública; entretanto, os autores destacam que a mudança irá ocorrer se a oportunidade for aproveitada pelo proponente, ou seja, pela coalizão dominante ou coalizões minoritárias.

Segundo Oliveira (2011), as perturbações internas ao subsistema, como elemento capaz de influenciar ou promover mudanças na política pública, foram inseridas a partir da literatura que evidencia os eventos como elemento importante. Segundo Kingdon (1995), nem sempre os problemas são evidenciados por indicadores, sendo necessários eventos ou crises para que os mesmos atraiam a opinião pública e demandem a atenção dos gestores públicos. 
Para Oliveira (2011:30), as perturbações internas "fornecem caminhos alternativos para maiores mudanças na política pública visto que possuem potencial de alterar o balanço de poder entre os participantes da política". Para Birkland (2004), alguns eventos têm a capacidade de atrair maior atenção pública. O autor destaca que eventos, como catástrofes, evidenciam falhas e vulnerabilidades ou negligências políticas, permitindo que novas informações adentrem no processo político.

Os choques internos e externos têm capacidade redistributiva de poder e recursos políticos críticos, podendo alterar significativamente as tensões entre diferentes coalizões. Para Oliveira (2011:31), "os choques internos confirmam ou reforçam as convicções de núcleo na política das coalizões minoritárias e criam ou aumentam as dúvidas dentro da coalizão de defesa dominante". Para Sabatier e Weible (2007), os choques internos indicam falhas nas políticas e no comportamento de uma coalizão dominante, afetando significativamente o sistema de convicções dos participantes políticos.

\section{Procedimentos metodológicos}

Esta pesquisa adotou uma abordagem qualitativa, cuja orientação favorece a compreensão de processos. Richardson e Peres (1999) consideram as pesquisas qualitativas caracterizadas pela compreensão de significados e de traços de determinadas situações.

A pesquisa realizada foi de caráter exploratório, que, segundo Gil (1999), permite desenvolver, esclarecer e modificar conceitos e ideias visando formular problemas e hipóteses para investigar posteriormente. Este trabalho enfocou a política formulada no âmbito da Fundação de Ciência e Tecnologia (Funcitec), que, posteriormente, transformou-se na Fundação de Amparo à Pesquisa e Inovação de Santa Catarina (Fapesc), com ênfase nos programas formulados no referido período. Este recorte foi adotado devido aos programas constituírem a dimensão explícita e objetiva da PCT do estado.

Para a consecução dos objetivos da pesquisa realizaram-se dois procedimentos principais, implementados de forma concomitante e/ou complementar. Um deles foi a coleta de dados secundários oriundos de relatórios e documentos oficiais das instituições envolvidas com a temática, principalmente documentos elaborados no período de 1989 a 2009, sendo os principais:

v Relatórios e estudos técnicos produzidos pelas organizações, principalmente do Funcitec e Fapesc, envolvidas com a PCT, no período de 1989 a 2009;

v Relatório da Comissão Especial da Política Científica, Tecnológica e de Inovação, da Assembleia Legislativa do Estado (Alesc), 2001;

v Legislação estadual pertinente ao tema.

Com o objetivo de reforçar os argumentos identificados nas pesquisas e nos materiais secundários, foram realizadas entrevistas em profundidade com 10 atores-chave do processo. 
Os atores entrevistados foram classificados de acordo com as quatro categorias: 1) comunidade de pesquisa; 2) burocratas; 3) designados politicamente; e 4) empresários. Em todas as entrevistas a modalidade adotada foi a semiestruturada, que combina perguntas abertas e fechadas. Segundo Minayo (2007), nessa modalidade o respondente tem a possibilidade de discorrer sobre o tema sem, necessariamente, se prender à indagação. As entrevistas foram orientadas de forma que permitissem relacionar as variáveis que compõem o modelo ACF. Conduziram-se as entrevistas com o objetivo de:

a) Caracterizar o posicionamento do entrevistado, suas ideias, convicções, recursos, possíveis constrangimentos no processo e sua percepção quanto a sua capacidade de influir na formulação da PCT, bem como sua percepção sobre a atuação de outros atores no processo;

b) Identificar a ocorrência de processos de aprendizagem orientada pela política e como esses foram percebidos pelo entrevistado;

c) Caracterizar a intermediação de interesses no setor, principalmente pelos agentes governamentais;

d) Identificar os atores mais relevantes no processo de formulação da PCT, e posicioná-los enquanto aliados ou opositores na disputa entre convicções, ideias e possíveis interesses;

e) Identificar as estratégias utilizadas e a ocorrência de mudança de posicionamento de atores relevantes ao longo do processo;

f) Identificar a interpretação do entrevistado sobre as condicionantes das mudanças implementadas.

Para a identificação dos participantes desta pesquisa adotou-se a técnica snowball (bola de neve), que consiste em seleção de uma amostra não probabilística na qual os primeiros participantes indicam os demais até que se atinja o objetivo proposto.

A análise dos dados ocorreu a partir da triangulação de dados secundários, entrevistas com atores-chave e constructos teóricos adotados na pesquisa. Para Vergara (2008), a triangulação de dados refere-se ao uso de diferentes fontes de dados, a partir de diferentes perspectivas temporais, espaciais e de informantes.

As transcrições das entrevistas não foram realizadas integralmente, focando apenas os conceitos sensíveis da pesquisa (Patton, 1990). Esses conceitos sensíveis se traduziram nas categorias de análise que derivam do modelo de coalizões de defesa. No quadro 1 se apresenta um resumo das mesmas.

Por fim, as coalizões foram identificadas com base nas variáveis convicções de núcleo profundo e convicções de núcleo na política pública. Segundo Weible e Sabatier (2009), as convicções de núcleo na política pública são ideias para formar as coalizões e definir a coordenação dos membros; entretanto, como muitos dos entrevistados não conseguiram afirmar claramente quais eram as convicções desse nível, a análise adotou as duas variáveis. 
Quadro 1

Categorias de análise

\begin{tabular}{|c|c|}
\hline Categoria & Conceito \\
\hline $\begin{array}{l}\text { 1. Papel dos atores na formulação } \\
\text { da PCT }\end{array}$ & $\begin{array}{l}\text { Identificação do papel dos atores na formulação da PCT no intuito de classificá-los em } \\
\text { diferentes coalizões. }\end{array}$ \\
\hline $\begin{array}{l}\text { 2. Coalizões, sistema de } \\
\text { convicções e recursos }\end{array}$ & $\begin{array}{l}\text { Identificação das coalizões, do sistema de convicç̃̃es e dos recursos adotados pelos } \\
\text { atores no intuito de influenciar a política pública. }\end{array}$ \\
\hline 3. Principais trajetórias da PCT & $\begin{array}{l}\text { Identificação de quais trajetórias ( } 1 \text {. aprendizagem orientada pela política; } 2 \text {. } \\
\text { perturbações externas; } 3 \text {. choques internos; } 4 \text {. impasse político) explicam melhor as } \\
\text { mudanças ocorridas na PCT. }\end{array}$ \\
\hline 4. Principais características da PCT & Identificação das principais características da PCT. \\
\hline 5. Conteúdo da política & Identificação dos principais programas que compuseram a PCT no período. \\
\hline
\end{tabular}

Fonte: Elaboração dos autores.

Para conformar as coalizões, buscou-se identificar como eixos centrais as convicções de núcleo profundo e as convicções de núcleo de política pública, ou seja, as preferências ou ideias dos atores quanto à PCT catarinense, suas diretrizes de atuação, seus instrumentos de fomento, as áreas prioritárias a serem beneficiadas etc. Foram identificadas graduações de convicções, variando do posicionamento "academicista", baseado na convicção de que a PCT deve atender prioritariamente às demandas da comunidade científica e ser avaliada pelos critérios internacionais da produção científica, como publicações, prometendo glórias e reconhecimento aos pesquisadores, até a convicção baseada na promoção da inovação, a qual atribui à PCT o papel de criar um ambiente propício para a geração de inovações e a interação entre os diferentes atores do subsistema.

Adotou-se também, como elemento para a caracterização das diferentes coalizões, a identificação dos recursos utilizados de acordo com as seguintes categorias: membros com autoridade formal institucionalizada; ressonância perante a opinião pública; informações e estudos apresentando relações de custo-benefício entre as diferentes alternativas; mobilização de tropas - elites políticas, recursos financeiros e liderança experiente.

\section{Apresentação dos resultados}

Os resultados desta pesquisa serão apresentados a partir das cinco categorias de análise do modelo de coalizões de defesa: 1. papel dos atores na formulação da PCT; 2. coalizões, sistema de convicções e os recursos; 3. principais trajetórias da PCT; 4. principais características da PCT; e 5. conteúdo da política. 


\subsection{0 papel dos atores}

As conclusões deste trabalho a respeito do papel dos atores no âmbito do subsistema da PCT catarinense corroboram as pesquisas de Dagnino $(2006,2007)$ e Dias $(2005,2009)$. Para esses autores a comunidade científica, os burocratas e os empresários são os atores que têm atuação destacada no âmbito da PCT. No caso de Santa Catarina, a comunidade científica também exerce um papel de destaque, sendo prevalente na formulação da PCT em todo o período analisado. Um reflexo desta prevalência é o fato de que a maioria dos dirigentes máximos das Secretarias de Estado responsáveis pela C\&T ou da Funcitec/Fapesc era oriunda do Centro Tecnológico (CTC), da Universidade Federal de Santa Catarina (UFSC), e principalmente do Departamento de Engenharia Mecânica. Identificou-se que a comunidade científica povoa densamente alguns dos principais órgãos do setor de C\&T no estado.

Em relação aos empresários, a partir da análise longitudinal, não se percebeu uma atuação destacada e contínua, sendo perceptíveis ações pontuais e vinculadas a demandas específicas do segmento. As respostas dos entrevistados destacaram que os empresários e a comunidade científica parecem atuar em lógicas distintas, corroborando a assertiva de Baumgarten (2004), que destaca as difíceis relações entre os dois segmentos, refletindo-se na ausência do empresariado em investimentos em C\&T e na própria formulação da PCT. Cabe destacar que os empresários se mantêm afastados da formulação da PCT devido a não perceberem benefícios diretos e de curto prazo, e principalmente pela descrença em relação à implementação da política formulada.

Em relação aos burocratas, diferentemente do que afirmam Dagnino (2006) e Dias (2009), esse ator não exerce papel destacado na formulação da PCT catarinense uma vez que seu contingente é minimizado devido à inexistência de carreira estruturada no estado. Entretanto, outro ator assume seu lugar, o designado politicamente, que também é recrutado no seio da comunidade científica, principalmente das universidades com maior destaque em SC como a UFSC, a Udesc e as do Sistema Acafe, e constitui o corpo administrativo das organizações responsáveis pela área como a Funcitec/Fapesc. Cabe destacar que a alternância no quadro de designados politicamente é uma exceção quando se trata da política científica e tecnológica catarinense, e muitos coordenadores de projeto atuam há alguns anos na instituição participando de diferentes governos, o que nos permite concluir que a comunidade científica, responsável pela indicação e manutenção dos mesmos, mantém um padrão de continuidade em relação à ocupação dos cargos.

A participação dos políticos na formulação da PCT catarinense não foi destacada, podendo a atuação tímida desse ator ser explicada pela lógica eleitoral, na qual o político não consegue capitanear dividendos políticos na área de C\&T e opta por não despender esforços em prol da causa, entretanto mantendo-se favorável à mesma uma vez que a própria sociedade exalta o papel da C\&T. A pesquisa também corrobora as assertivas de Dagnino (2006) e Dias (2009), ao afirmarem que os políticos exercem um papel semelhante ao dos burocratas e mesmo dos empresários. A postura desse ator também pode ser explicada a partir da tipolo- 
gia de Gormley, que distingue as políticas com base no nível de saliência e de complexidade (Secchi, 2010). A partir destas variáveis, são criadas quatro tipologias.

Quadro 2

Tipologia de Gormley

\begin{tabular}{|cccc|}
\hline & & \multicolumn{2}{c|}{ Complexidade } \\
\cline { 3 - 4 } & & Alta & Baixa \\
\cline { 2 - 4 } Saliência & Alta & $\begin{array}{c}\text { Política de sala operatória } \\
\text { (operating room politics) }\end{array}$ & Política de audiência \\
\cline { 2 - 4 } & Baixa & Política de sala de reuniões & (hearing room politics) \\
\cline { 2 - 4 } & & (board room politics) & Política de baixo escalão \\
& & & (street level polítics) \\
\hline
\end{tabular}

Fonte: Secchi (2010:20).

A PCT se enquadra como uma política de sala de reuniões, que, segundo Secchi (2010), consiste em uma política com baixa saliência, ou seja, não atrai a atenção do público e ao mesmo tempo apresenta-se como de alta complexidade. Essa classificação ajuda a compreender o baixo interesse dos políticos na PCT, uma vez que a mesma demanda conhecimentos técnicos, os quais "apenas a comunidade científica domina", e não ganha destaque perante os eleitores.

Conclui-se que a PCT pode ser interpretada como uma política de cunho mais técnico, que, na tipologia de Bozeman e Pandey (Secchi, 2010), significa dizer que o conteúdo técnico da política favorece a prevalência do ator que domine a área tecnicamente, ou seja, a comunidade científica. Após a identificação do papel dos atores, buscou-se conformar as coalizões, o sistema de convicções e os recursos adotados, a serem apresentados no próximo item.

\subsection{As coalizões, o sistema de convicções e os recursos}

A análise de política pública por meio do modelo de coalizões de defesa tem como um dos principais elementos a identificação das coalizões que atuam no subsistema da política analisada. O sistema de convicções e os recursos adotados pelos atores são variáveis que auxiliam na delimitação das coalizões. O sistema de convicções permite identificar quais atores compartilham dos mesmos axiomas ontológicos e das visões a respeito da determinada área em estudo e os recursos permitem a identificação de estratégias utilizadas para influenciar a política pública. Neste estudo identificamos apenas uma coalizão atuando no subsistema da PCT catarinense, ou seja, não foi possível conformar coalizões diferentes a partir do seu sistema de convicções. Entretanto, observou-se que atores de diferentes filiações (comunidade científica, empresários, designados politicamente) cooperaram visando o alcance de objetivos semelhantes e foram considerados integrantes de uma coalizão ampliada.

Quando indagados a respeito das coalizões dominante e minoritária, os entrevistados foram unânimes em afirmar que a coalizão dominante no período foi a comunidade científica. 
Entretanto, ao se analisar a configuração das relações e as interações entre os diferentes atores, evidenciou-se que o núcleo central dessa "grande coalizão" era a comunidade científica, a qual também não formava um grupo monolítico, havendo divisões em seu seio, sendo o grupo dominante originário da UFSC e, principalmente, do Departamento de Engenharia Mecânica.

A pesquisa corroborou a assertiva de Baumgarten (2004), que afirma que a atuação dos cientistas não está restrita aos laboratórios, pois os mesmos atuam em arenas compostas por agências de financiamento, indústrias, editoras, diretores de instituições científicas, universidades, fornecedores etc. As relações entre cientistas e não cientistas implicam negociações e traduções, permitindo que se criem pontes de diálogo entre os diferentes atores. Segundo a autora, essas relações configuram-se como de dependência mútua em termos de recursos e suporte.

Também corroboramos a conclusão de Dagnino (2007), que indica que a comunidade científica acaba por ocupar o papel da própria empresa na definição da PCT. Os pesquisadores-empresários têm sido apelidados de "alto clero das ciências duras" ou de "acadêmicos empreendedores", habilitados a interagir com as "empresas inovadoras" nacionais, com as "empresas de alta tecnologia" e, cada vez mais, com as multinacionais.

Essa vocalização dos interesses dos empresários por meio da comunidade científica origina-se na própria relação que esses dois atores estabeleceram no âmbito da PCT. A maior parte das empresas inovadoras tem origem nas universidades catarinenses, principalmente na UFSC e mais especificamente em seu Centro Tecnológico (CTC). Como afirma um entrevistado, "a maioria dos empresários ligados à ciência e tecnologia foi aluno da UFSC, principalmente dos cursos de engenharia, e muitos dos dirigentes da Funcitec/Fapesc foram nossos professores, o que nos permitia um acesso informal e um bom relacionamento".

Em relação ao sistema de convicções da coalizão da inovação, identificou-se que as convicções de núcleo profundo amparavam-se nas políticas de ciência e tecnologia nacionais, principalmente advindas do CNPq e do MCT. Ou seja, eram políticas públicas voltadas para o fomento e o apoio ao desenvolvimento de pesquisas consideradas estratégicas e de ponta, a serem executadas pelos pesquisadores vinculados às universidades e que seriam selecionados por meio de editais, avaliados por consultores ad hoc. Esse modelo privilegiava e concentrava a disponibilização de recursos para áreas tecnológicas e das ciências "exatas", como engenharias, física, química e biologia. O sistema de convicções de núcleo profundo dessa coalizão também evolui conforme as diretrizes da PCT brasileira, estando num primeiro momento voltada à promoção da competitividade da indústria catarinense, principalmente nos anos 1990, e depois assumindo como principal objetivo a promoção da inovação nos anos 2000.

No caso da PCT catarinense, não foi identificada uma variação substantiva no sistema de convicções de núcleo profundo ao longo do tempo, uma vez que o sistema de convicções, originado a partir do pensamento da comunidade científica pertencente ao Centro Tecnológico (CTC), foi dominante ao longo do período analisado e seguiu a evolução natural desse segmento no subsistema. O sistema de convicções de núcleo profundo disseminado pela coalizão de inovação visava à interação entre universidades, institutos de pesquisa, como a Fundação Certi, incubadoras de empresas e empresas na geração de produtos e processos de alta tecnologia. 
A comunidade científica voltada para a pesquisa aplicada e para a produção de produtos e processos de alta tecnologia sempre se relacionou com os empresários e buscou influenciar os governos na formulação da PCT catarinense, principalmente para que a mesma realizasse ações alinhadas com esse sistema de convicções. Entretanto, uma parte da comunidade científica não compartilhava do sistema de convicções voltado para a pesquisa aplicada, adotando uma postura em prol da pesquisa básica e voltada para publicações em periódicos considerados relevantes. Pequena parcela da comunidade científica reivindicava que a política e principalmente os recursos fossem direcionados para a pesquisa básica, reproduzindo o padrão do modelo nacional que há décadas promovia a ciência básica nas universidades públicas, como ilustra a fala de um entrevistado: "até hoje eles (comunidade científica) estão no modelo da pesquisa, alegando que a ciência precisa primeiro ser desenvolvida para depois ser aplicada", reforçando o argumento de que uma parcela da comunidade científica ainda está ligada ao modelo linear de ciência.

Para alguns entrevistados a política científica e tecnológica catarinense sempre teve um diferencial em relação aos modelos dos demais estados e da própria União. Essa diferença diz respeito à estreita ligação entre a universidade, principalmente a UFSC, e as empresas. Essa forte relação universidade-empresa pautou-se nos modelos internacionais em que muitos pesquisadores do CTC realizaram seus mestrados e doutorados.

Identificou-se que o grupo vinculado à pesquisa aplicada sempre se sobressaiu e conseguiu exercer maior influência na formulação da PCT em detrimento do grupo vinculado à pesquisa básica. A coalizão da inovação se pautou no modelo evolucionário e sempre atuou em prol da criação de um ambiente propício à interação dos atores constituintes da tríplice hélice (universidades, empresas e governo), enquanto os membros da comunidade científica "academicistas" eram entusiastas do modelo linear. Um elemento explicativo para o destaque do grupo vinculado à pesquisa aplicada é sua forte relação com as empresas consideradas inovadoras. Um entrevistado destacou que os empresários influenciavam o governo estadual a apoiar projetos realizados pelas universidades e pelas empresas inovadoras, mesmo porque esses empresários eram responsáveis pela geração de receita ao estado por meio de tributos e patrocinadores de campanhas.

Em relação às convicções com núcleo na política pública, configuradas pela questão substantiva do subsistema ou geográfica, pela percepção causal, por estratégias básicas e posições políticas para se executar as convicções de núcleo profundo em um dado subsistema político (Weible et al., 2009; Sabatier e Weible, 2007), ficou caracterizada pelas diretrizes nacionais, como: i) a formação de recursos humanos para a área, por meio de apoio a programas de pós-graduação e a concessão de bolsas; ii) fomento a incubadoras de empresas e a empresas inovadoras; iii) fomento a pesquisa básica e aplicada, principalmente voltadas à tecnologia; e iv) inclusão digital por meio da Rede Catarinense de Ciência e Tecnologia (RCT).

No terceiro nível são identificadas as convicções de aspectos secundários, que abrangem considerações instrumentais sobre como implementar a política, sendo essas as mais suscetíveis a mudanças ao longo do tempo (Weible e Sabatier, 2009; Sabatier e Weible, 2007). 
Identificou-se que o terceiro nível sofreu mudanças ao longo do tempo e em virtude das demandas dos beneficiários, principalmente da comunidade científica.

Um aspecto secundário debatido pela coalizão da inovação diz respeito aos instrumentos de repasse de recursos para os pesquisadores e as empresas. Em 20 de abril de 2005, por meio do Decreto número 3.071, foi permitida a execução descentralizada de recursos da Fapesc com transferência direta de recursos financeiros às pessoas físicas, operação impossível de ser realizada até a referida data e que consistia em uma antiga demanda dos pesquisadores, uma vez que a partir deste instrumento jurídico poderiam gerir os recursos diretamente sem a necessidade de um repasse para as instituições de pesquisa as quais estavam vinculados. $\mathrm{E}$ em 2009, por meio do Decreto 2.372, foi regulamentado o instrumento de subvenção econômica, instituído pela Lei Catarinense de Inovação, e que permitiu o repasse de recursos a empresas catarinenses visando a promoção de processos, produtos e serviços considerados inovadores. O referido decreto viabilizou o aporte de recursos financeiros e a participação societária do estado em empresas, atendendo a uma reivindicação dos empresários e da própria comunidade científica, e regularizando um canal de fomento.

O diagrama a seguir apresenta os três níveis de convicções da coalizão da inovação.

Figura 3

Diagrama da estrutura de convicções da coalizão da inovação

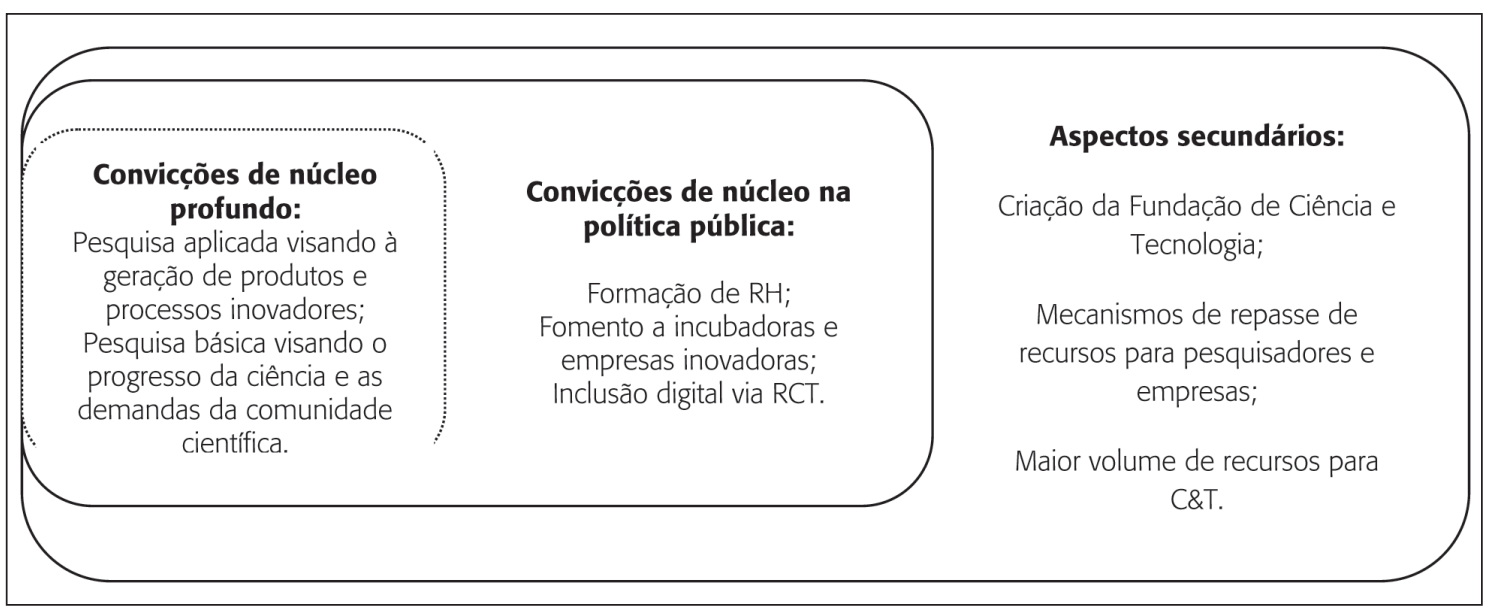

Fonte: Elaboração dos autores

\subsection{Principais trajetórias}

Em relaçã0o às principais trajetórias que ajudam a explicar as mudanças na PCT catarinense no período analisado, conclui-se que as quatro trajetórias (aprendizagem orientada pela política; choques externos; choques internos; impasse de política) têm capacidade de explicar 
as mudanças no âmbito da PCT catarinense. Entretanto, todos salientaram que a trajetória aprendizagem orientada pela política pública destaca-se perante as demais.

Como a PCT catarinense constitui um subsistema imaturo, boa parte dos envolvidos buscava colaborar para aprimorá-la, e como não havia uma coalizão de oposição que pudesse influenciar os rumos da política, ela tendeu a progredir por meio de aprimoramentos. Outro elemento que contribuiu para a progressão aliada ao aprendizado foi a manutenção dos principais atores nas posições decisórias, ou seja, ao longo do período, os membros da comunidade científica sempre estiveram de alguma forma vinculados e próximos das esferas decisórias que envolveram a formulação da PCT; como exemplo, cita-se a ocupação de cargos decisórios na Funcitec/Fapesc, o que contribuiu para um processo efetivo de aprendizagem.

No subsistema da PCT não houve nenhum impasse político capaz de provocar mudanças profundas ou condicionar a trajetória da política. Segundo um entrevistado, a abertura comercial promovida pela gestão Collor, em âmbito federal, pode ser classificada como uma perturbação externa que afetou o subsistema da PCT, mas não provocou mudanças radicais, apenas expôs algumas empresas a uma concorrência mais acirrada; entretanto, como a maioria das empresas do período tinha seus clientes sediados em território catarinense, elas não foram afetadas seriamente.

E também foi identificado que a perturbação externa proveniente do subsistema de ciências agrárias influenciou a trajetória da PCT a partir de 2005, principalmente em relação à disputa de recursos entre o grupo das agrárias e a comunidade científica das demais disciplinas.

O grupo das ciências agrárias, mesmo pertencendo a outro subsistema de política pública, teve uma atuação que influenciou o subsistema da PCT, desde a constituinte estadual, em 1989. Nesse período, a comunidade científica reivindicava a inclusão de um percentual mínimo na Constituição a ser destinado a ciência e tecnologia. Amparado no exemplo das demais unidades federativas, o percentual negociado com o governo do estado oscilava entre 0,5 e 1,0\%. Entretanto, no período da votação da proposta, os segmentos vinculados às ciências agrárias propuseram seu apoio à aprovação do art. 193, condicionando o apoio à elevação do patamar e à destinação de 50\% do mesmo para as ciências agrárias. Nessa negociação, o percentual constitucional foi alçado ao patamar de $2 \%$, e tanto a comunidade científica vinculada às demais disciplinas quanto o grupo das ciências agrárias foram beneficiados. Entretanto, a gestão da área e a aplicação dos recursos foram divididas por meio da criação do Funcitec, em 1990, e do Fundo Estadual de Pesquisa Agropecuária (Fepa), em 1992. O grupo das ciências agrárias e o das ciências exatas voltariam a disputar recursos e buscar influenciar a PCT sob a égide do mesmo arcabouço institucional a partir da criação da Fapesc, em 2005.

\subsection{Principais características e conteúdo da PCT}

Em relação às principais características da PCT no período, os entrevistados afirmaram que a mesma era uma emulação das políticas nacionais vigentes no período, principalmente no 
que diz respeito às ações de fomento. Também destacaram o papel exercido pela Capes e pelo CNPq na conformação das PCTs em âmbito subnacional.

A vinculação universidade-empresa sempre foi uma característica destacada e que ganhou força a partir dos anos 2000, principalmente com base na guinada à inovação que as PCTs brasileira e catarinense realizaram.

Nenhum dos entrevistados atribuiu à PCT catarinense o aspecto de não tomada de decisão (nondecision-making), e muitos ressaltaram que a PCT era elaborada nos respectivos governos, ou seja, as decisões a respeito do que se priorizar eram tomadas. Entretanto, a decisão de aportar os recursos sempre foi algo estimulado pela comunidade científica, ou seja, uma pressão exercida sobre os gestores da área e que poucas vezes foi efetiva.

Identificou-se a elaboração de vários planejamentos para a área de C\&T durante os governos. Entretanto, a descontinuidade e a pulverização de programas são características marcantes do conteúdo da política. Outro elemento importante, e já debatido por Ouriques (2004) e Oening (2006), diz respeito ao baixo volume de aplicação dos recursos em comparação com o patamar constitucional estabelecido.

O conteúdo da política, traduzido nos programas da Funcitec/Fapesc, sempre foi definido de acordo com as diretrizes das Políticas Nacionais de C\&T, mesmo porque muitos deles só foram formulados a partir da contrapartida financeira de órgãos como o CNPq e o MCTI. As principais diretrizes desses órgãos eram a: i) formação de recursos humanos, ii) apoio a empresas inovadoras e a incubadoras de empresas, iii) apoio a infraestrutura de pesquisa etc.

\section{Considerações finais}

O presente trabalho analisou a trajetória da PCT catarinense à luz do modelo de coalizões de defesa. As conclusões a respeito do papel dos atores no âmbito do subsistema da política científica e tecnológica catarinense corroboram as pesquisas de Dagnino (2006, 2007) e Dias (2005, 2009). Para esses autores, a comunidade científica, os burocratas e os empresários são os atores que têm atuação destacada no âmbito da PCT. No caso de Santa Catarina, a comunidade científica também exerce um papel de destaque, sendo prevalente na formulação da PCT em todo o período analisado.

Em relação aos empresários, a partir da análise longitudinal, não se percebeu atuação destacada e contínua, sendo perceptíveis ações pontuais e vinculadas a demandas específicas do segmento.

Em relação aos burocratas, diferentemente do que afirmam Dagnino (2007) e Dias (2009), esse ator não exerceu papel destacado na formulação da PCT catarinense no período analisado. Entretanto, outro ator assume seu lugar, o designado politicamente, que também é recrutado no seio da comunidade científica, principalmente das universidades com maior destaque em SC como: a UFSC, a Udesc e as universidades vinculadas à Associação Catarinense das Fundações Educacionais (Acafe). 
A participação dos políticos na formulação da PCT catarinense não foi destacada, podendo a atuação tímida desse ator ser explicada pela lógica eleitoral, na qual o político não consegue capitanear dividendos políticos na área de C\&T e opta por não despender esforços em prol da causa, entretanto mantendo-se favorável à mesma, uma vez que a própria sociedade exalta o papel da C\&T. Outro elemento explicativo para a baixa participação e interesse dos políticos reside no fato de a PCT apresentar baixa saliência, ou seja, constitui uma política de sala de reuniões de acordo com a tipologia de Gormley (Secchi, 2010).

Esta pesquisa identificou uma coalizão ampliada no âmbito da PCT catarinense no período de 1989 a 2009. A mesma foi denominada "coalizão da inovação", composta pela comunidade científica, designados politicamente, políticos e empresários.

Identificou-se que as convicções de núcleo profundo da coalizão da inovação amparavam-se nas políticas de ciência e tecnologia nacionais, principalmente advindas do CNPq e do MCT. Ou seja, eram políticas públicas voltadas para o fomento e o apoio ao desenvolvimento de pesquisas consideradas estratégicas e de ponta, a serem executadas pelos pesquisadores vinculados às universidades e que seriam selecionados por meio de editais, avaliados por consultores ad hoc. O sistema de convicções de núcleo profundo disseminado pela coalizão de inovação visava à interação entre universidades, institutos de pesquisa, como a Fundação Certi, incubadoras de empresas e empresas na geração de produtos e processos de alta tecnologia.

As convicções de núcleo na política pública também foram influenciadas pelas diretrizes nacionais, sendo as principais diretrizes: i) a formação de recursos humanos para a área, por meio de apoio a programas de pós-graduação e a concessão de bolsas; ii) fomento a incubadoras de empresas e a empresas inovadoras; iii) fomento a pesquisa básica e aplicada, principalmente voltadas à tecnologia; e iv) inclusão digital por meio da Rede Catarinense de Ciência e Tecnologia (RCT).

E, em relação aos aspectos secundários, a coalizão da inovação divergiu a respeito da criação da Fundação e posteriormente reivindicou a criação de mecanismos de repasse que dessem maior flexibilidade e autonomia aos pesquisadores para a aplicação dos recursos.

Em relação às principais trajetórias que ajudam a explicar as mudanças na PCT catarinense no período analisado, conclui-se que as quatro trajetórias (aprendizagem orientada pela política; choques externos; choques internos; impasse de política) têm capacidade de explicar as mudanças no âmbito da PCT catarinense. Entretanto, todos salientaram que a trajetória aprendizagem orientada pela política pública destaca-se perante as demais.

Esta pesquisa corrobora os trabalhos de Dagnino (2007) e Dias (2009) e conclui que a PCT pode ser interpretada como uma política de cunho mais técnico, que, na tipologia de Bozeman e Pandey (Secchi, 2010), significa dizer que o conteúdo técnico da política favorece a prevalência do ator que domine a área tecnicamente, ou seja, a comunidade científica. E, como se identificou, o fato de a PCT também constituir uma política de sala de reuniões, com baixa saliência e alta complexidade, pode ser um elemento explicativo para o desinteresse dos políticos. 


\section{Referências}

BAUMGARTEN, Maíra. Comunidades ou coletividades? O fazer científico na era da informação. Política e Sociedade, Florianópolis, n. 4, p. 97-136, abr. 2004.

BIRKLAND, Thomas A. Learning and policy improvement after disaster: the case of aviation security. American Behavioral Scientist, v. 48, n. 3, p. 341-364, nov. 2004.

DAGNINO, Renato P. A comunidade de pesquisa dos países avançados e o processo de elaboração da política de ciência e tecnologia. Revista Brasileira de Ciências Sociais, v. 21, n. 61, p. 191-201, jun. 2006.

DAGNINO, Renato P. Ciência e tecnologia no Brasil: o processo decisório e a comunidade de pesquisa. Campinas: Editora da Unicamp, 2007.

DAGNINO, Renato P.; DIAS, Rafael B. A política de C\&T brasileira: três alternativas de explicação e orientação. Revista Brasileira de Inovação, v. 6, n. 2, p. 373-403, jul./dez. 2007.

DIAS, Rafael B. A política científica e tecnológica latino-americana: relações entre enfoques teóricos e projetos políticos. Dissertação (mestrado) — Instituto de Geociências, Universidade de Campinas, Campinas, 2005.

DIAS, Rafael B. A trajetória da política científica e tecnológica brasileira: um olhar a partir da análise de política. Tese (doutorado) — Instituto de Geociências, Universidade de Campinas, Campinas, 2009.

ETZKOWITZ, Henry; LEYDESDORFF, Loet. The dynamics of innovation: from national systems and "Mode 2" to a triple helix of university-industry-government relations. Research Policy, v. 29, p. 109-123, 2000.

GIBBONS, Michael et al. The new production of knowledge: the dynamics of science and research in contemporary societies. Londres: Sage, 1994.

GIL, Antonio C. Métodos e técnicas de pesquisa social. 5. ed. São Paulo: Atlas, 1999.

KINGDON, John W. Agendas, alternatives, and public policies. 2. ed. Nova York: Harper Collins, 1995.

MINAYO, Maria C. S. Pesquisa social: teoria, método e criatividade. Petrópolis: Vozes, 2007.

NOWOTNY, Helga et al. Re-thinking science: knowledge and the public in an age of uncertainty. Cambridge: Polity Press; Blackwell Publishers Inc, 2001.

OENING, Karla S. O processo de adaptação estratégica da Fundação de Apoio à Pesquisa Científica e Tecnológica do Estado de Santa Catarina - Fapesc. Dissertação (mestrado) - Centro Socioeconômico, Programa de Pós-Graduação em Administração, Universidade Federal de Santa Catarina, Florianópolis, 2006.

OLIVEIRA, Ana P. As mudanças na política de saneamento de Belo Horizonte no período de 1993 a 2004: uma análise a partir do modelo de coalizão de defesa. Tese (doutorado) - Universidade Federal de Minas Gerais, Belo Horizonte, 2011. 
OURIQUES, Nildo D. Ciência e tecnologia em Santa Catarina. Florianópolis: Ed. do Autor, 2004.

PATTON, Michael Q. Qualitative evaluation and research methods. Newbury Park, Calif.: Sage Publications, 1990.

RICHARDSON, Roberto J.; PERES, José S. Pesquisa social: métodos e técnicas. 3. ed. rev. e ampl. São Paulo: Atlas, 1999.

SABATIER, Paul A. Knowledge, policy-oriented learning, and policy change. Knowledge: Creation, Diffusion, Utilization, v. 8, n. 4, p. 649-692, jun. 1987.

SABATIER, Paul A. Top-down and bottom-up approaches to implementation research. A critical analysis and suggested synthesis. Journal of Public Policy, v. 6, n. 1, p. 21-48, 1986.

SABATIER, Paul A. Toward better theories of the policy process. Political Science and Politics, n. 24, p. 144-156, jun. 1991.

SABATIER, Paul A.; JENKINS-SMITH, Hank. Policy change and learning: the advocacy coalition approach. Boulder, CO: Westview Press, 1993.

SABATIER, Paul A.; MAZMANIAN, Daniel. The conditions of effective implementation: a guide to accomplishing policy objectives. Policy Analysis, v. 5, n. 4, p. 481-504, 1979.

SABATIER, Paul A.; WEIBLE, Christopher M. The advocacy coalition framework: innovations and clarifications. In: SABATIER, Paul A. (Ed.). Theories of the policy process. Boulder, CO: Westview Press, 2007. p. 189-220.

SANTA CATARINA. Decreto nํㅜㄴ.372. Diário Oficial do Estado de Santa Catarina. Florianópolis: Imprensa Oficial, 2009.

SCHWARTZMAN, Simon; BATH, Sérgio; BIATO, Oswaldo. Um espaço para a ciência: a formação da comunidade científica no Brasil. Brasília: Centro de Estudos Estratégicos, 2001.

SECCHI, Leonardo. Políticas públicas: conceitos, esquemas de análise, casos práticos, 2. ed. São Paulo: Cengage Learning, 2010.

VERGARA, Sylvia C. Métodos de pesquisa em administração. 3. ed. São Paulo: Atlas, 2008.

WEIBLE, Christopher M.; SABATIER, Paul A. Coalitions, science, and belief change: comparing adversarial and collaborative policy subsystems. The Policy Studies Journal, v. 2, n. 37, p. 195-212, 2009.

Luiz Ricardo de Souza é mestre em administração pela Universidade do Estado de Santa Catarina. Professor colaborador na Universidade do Estado de Santa Catarina (Esag/Udesc). E-mail: luizricardo. souza@gmail.com.

Leonardo Secchi é Ph.D. em ciências políticas pela Universidade de Milão, Itália. Professor na Universidade do Estado de Santa Catarina (Esag/Udesc). E-mail: leosecchi@gmail.com. 